\title{
A Study of Gender Discrimination Faced by Professional Women in Pakistan- - A Case Study of Rahim Yar Khan Region
}

\author{
Muhammad Sabil Farooq ${ }^{1 *}$, Prof. Yuan Tong Kai ${ }^{1}$, Nazia Feroze ${ }^{b}$ \\ ${ }^{123}$ Department of Sociology and Anthropology, Zhou Enlai School of Government, Nankai University \\ Tianjin, P.R China
}

Authors Details:

Muhammad Sabil Farooq is a PhD Sociology from Nankai University, Tianjin China. He has been served seven years in different national and international developmental organizations as a research analyst. He can be reached at sabilfarooq@hotmail.com or 1120146006@mail.nankai.edu.cn.Yuan Tongkai is PhD Professors at the Zhou Enlai School of Government, Nankai University China. He can be reached at misbahirm@hotmail.com. Nazia Feroze is an MA anthropology candidate at the Zhou Enlai School of Government, Nankai University. She can be reached at naziaferoze@163.com.

Their mailing address is:Zhou Enlai School of Government, Nankai University, 94 Weijin Road, Tianjin 300071, China.

Abstract: As a traditional Muslim country, the problem of gender discrimination in employment among women in Pakistan is more common. If we let it develop without taking measures, it will seriously restrict the speed and quality of Pakistan's domestic economic development in the long run. In this study, the author obtained the first-hand information on the employment status of professional women in the Rahim Yar Khan region of Pakistan through questionnaire survey, supplemented by the public data of the Federal Statistical Office of Pakistan, and combined with the existing research results of the predecessors. Sex discrimination in employment of professional women in Pakistan. Through the collection of the data obtained from the questionnaire, the author found that economic factors are one of the main factors that cause local women to encounter gender discrimination in employment. Specifically, it includes the imbalance of labor supply and demand and the pursuit of maximum profits. At the same time, the traditional Muslim culture, women's own literacy and the imperfect legal system in Pakistan are also the key factors that cause female employees in the local area to encounter gender discrimination in employment. Women's gender discrimination in employment is a universal problem. In any country in the world, gender discrimination may exist as long as women are involved in the work. Based on Pakistan's basic national conditions and relevant professional knowledge, the author provides several suggestions for eliminating the problem of gender discrimination in employment for local female employees in Pakistan.

1) The Pakistani government should further promote the domestic economic growth, increase the number of jobs, and ease the imbalance between the supply and demand of labor. At the same 
time, encourage self-employment and provide corresponding policy support. A variety of measures are also intended to address local gender discrimination in employment for women.

2) The government's leadership accelerates the transformation of the concept of the whole society. On the one hand, it requires the whole society to correctly understand the social status and social contribution of women, and strives to bring the concept of equality between men and women into the hearts of the people. It is intended to encourage qualified women to go out of the family to participate in social work. At the same time, correctly guide corporate values. Enterprises should not unilaterally pursue the maximization of interests, and should take the initiative to assume social responsibilities.

3) Women should also actively and consciously improve their literacy. Including not only active learning advanced cultural knowledge and professional skills. For the professional skills that have already been mastered, you must study harder and make yourself more and more progressive. At the same time, families should guarantee that girls of the appropriate age receive the education they deserve, so that they can gather their strengths in the workplace in the future.

Key Words: Pakistan; Rahim Yar Khan; female employment; gender discrimination.

\section{Introduction}

\section{Problem statement}

Since the entry of human history into the patriarchal society, men have gradually become the dominant family members due to their inherent physiological characteristics, and gender discrimination against women has also sprouted. After thousands of years of human civilization development, the social division of "male dominated, female subordinates" has long been deeply rooted in the hearts of the people. Sex discrimination against women has long been ubiquitous in all aspects of society. In the author's view, the gender discrimination that people usually refer to refers to the treatment of different gender members, and in most cases, the male members' differential treatment for women. After the 1940s, the economies of the world have developed rapidly. The level of spiritual civilization in human society has increased year by year. The slogan of advocating equality between men and women and pursuing equality between men and women is constantly mentioned and widely recognized by the people of all countries. However, discrimination against women still exists in many places. Among the various components of social groups, women and girls are recognized as vulnerable groups. The social reality today is that 
women may face gender discrimination in various situations at all levels of their age or at any stage of their social role. In their childhood, girls did not meet their daily needs and could not receive a complete formal education like a boy. When they grow up, they are tied up in the family by their cumbersome housework when they are wives and mothers. The deepest reason for this is hunger and poverty. The vast majority of economically disadvantaged women and girls spend their entire lives in the discrimination of others. In most cases, gender discrimination for working women is usually due to the employer's belief that she is a woman and is not willing to pay for her due treatment. Women can go out and work in the home. In most cases, they are either not accepted by the employer or pay the same amount of work as male members, but they cannot get the same pay. Or the employer's inherent thinking is that certain leadership positions should be borne by men and rejected by female staff. Secondly, in some aspects that cannot be easily detected, the gender discrimination that women encounter cannot be ignored. For example, in family life, you have to bear housework and may be bullied or abused. Even at work, it is possible to encounter the employer's glare, contempt, or be deprived of equal rights by the employer in disguise. People's inherent thinking that gender discrimination usually comes from strangers. But in fact, the majority of the main implementers of gender discrimination against women are not outsiders, but from the immediate family members of the female members of the father, husband, brothers. And because of the weak awareness of rights protection, female members are trapped in the family in some poor areas. They are unable to participate in normal social communication, lose their understanding and improve their opportunities, and also lose the right to improve their own quality of life and improve their family life.

Among them, the "Muslim World Countries" is the "hardest hit" for female gender discrimination. Influenced by the traditional Muslim culture, patriarchies has long been ingrained in the hearts of local people. And not just men, local women have long been eccentric about the way women encounter gender discrimination. A few women have objected to the second, but the end result is no longer. Humanity has entered the new century for almost 20 years, and gender equality is advocated on a global scale. What's more, the Qur'an also mentions that everyone is equal before Allah. And the Qur'an has never banned women from having a career or taking part in work! The author is from Pakistan and is a woman herself. She is deeply indignant at the issue of gender discrimination faced by her female compatriots. I also hope that I can do my part for my female compatriots to fight for their legitimate rights and interests. 
Islamic Republic of Pakistan, referred to as Pakistan. More than $90 \%$ of the country's democracy believes in Islam. It belongs to a typical multi-ethnic Islamic country. Since the independence of the 1950s, Pakistan's domestic economic structure has been based on agriculture, and its domestic industrial base is weak and its development is relatively slow. In the new century, Pakistan's domestic economic structure has gradually changed from agricultural-based to servicebased, with agricultural output accounting for about $24 \%$ of gross domestic product (GDP). The tertiary industry accounts for about 53\% of GDP, of which wholesale and retail trade accounts for about $30 \%$ of the tertiary industry. (http://www.pbs.gov.pk) Pakistan, as a friendly neighbor of China, is a traditional Islamic country [1]. It has a strong Islamic style in economic, cultural, religious, and legal aspects. It is influenced by both traditional Islamic culture and social development. Pakistani female staff usually enjoy the advantages of preferential policies from the government, but also suffer from disadvantages such as religious gender discrimination [2]. With the continuous development of Pakistan's domestic economy, Pakistan's domestic industrial structure has also developed rapidly. More and more new jobs and new jobs are beginning to emerge. Correspondingly, more and more women are starting to work and participate in social work with male members. Therefore, we will see female entrepreneurs, female lawyers, and female police officers and so on. Of course, there is also the pride of the Islamic world - Benazir Bhutto and so on. But despite this, the elite is only a minority. For the majority of basic female practitioners in Pakistan, gender discrimination in employment is still one of the biggest problems in the workplace. This includes, but is not limited to, the differential treatment of female employees, and even in most industries, women have few employment opportunities, or women do not enjoy equal employment opportunities [3]. Although the Pakistani government is unanimously committed to promoting women's employment, the overall situation is still not satisfactory - the proportion of female employees is still very small, and gender discrimination is still severe. For female employees, all kinds of gender discrimination will create obstacles for their future career path.

The problem of women's encountering discrimination has long existed. The reason is that the other factors work together. For example, female physiological factors, female psychological factors, national political system factors, social traditional cultural factors and so on. At the same time, the study of female gender discrimination is also closely related to the related research of sociology, political economy and female psychology. However, no matter from which angle to specifically study and analyze women's employment gender discrimination, we should pay attention to the employment status of female groups. To explore women's gender discrimination in 
employment, we should not only consider the factors of female individual level, but also focus on local social and political systems, economic structure, social traditional culture and other factors. In the context of the current slowdown in global economic growth, employment has become one of the important issues facing countries, and female employment has become an urgent problem to be solved. The current employment distress in Pakistan's domestic women is concentrated in the number of jobs and high unemployment. Business owners are more willing to hire male job seekers and reject women when they have choices. This leads to women in the modern workplace or passively accepting jobs with poor working conditions, relatively low incomes, or simply not finding jobs. In the long run, this phenomenon cannot be effectively stopped or an effective solution cannot be found. The situation of female staff in the workplace will only become more and more serious. There is also no solution to the problem of female employees' gender discrimination in employment. The author is from the Rahim Yar Khan region of Pakistan. This city where I gave birth to me can be seen as a microcosm of Pakistani society. Therefore, it was selected as the target area of this study. Similarly, as a woman, the discrimination that women encounter in the workplace can easily resonate, and the author is also willing to explore the causes of these problems. Whether it is in Pakistan, in China, or in any corner of the world!

\section{Research Results of the study}

Women's gender discrimination in employment is a common problem in every country in today's society. The exploration of gender discrimination in women's employment is also one of the hot issues that scholars from all countries pay close attention to. In the course of research and discussion on related issues, Western economists have formed a new research branch of economics research based on economics - labor discrimination economics. The conclusions of the study indicate that the main measure used by employers when hiring staff is to maximize profits. Sociologists have formed another set of research theories based on social culture and gender. At the same time, different schools of feminism also launched a series of research and exploration on the issue of gender discrimination in women's employment based on their own perspectives.

Due to the development of Western traditional sociology, the issue of discrimination has always been widely explored by scholars of sociology, anthropology, psychology and other related disciplines as an important social issue. Because of the differences in the root causes and mechanisms of discrimination, the mainstream concepts of Western labor market discrimination theory can be divided into three categories [4]. One is to blame the causes of discrimination on 
personal prejudice. This concept is to discuss discrimination in the framework of market competition equilibrium. It can be understood that discrimination is caused by market competition. Another view is that the root of discrimination lies in market monopoly. This view denies that discrimination is not caused by market competition. The third round of view is that the root of discrimination lies in the choices made by the business owners in conformity with the development of the market economy.

As the founder of the theory of discrimination in the labor market, Berk pointed out that after a series of in-depth explorations on women's gender discrimination in employment, business owners only choose female job seekers in the following three situations.

1) The labor remuneration paid by the employer to the woman is enough to offset the loss of profits caused by the employment efficiency of the female job seeker due to childbirth and family factors;

2) The labor remuneration paid by the business owner to the woman is enough to offset the loss of profits caused by the higher production costs caused by the employment of female job seekers;

3) Female job seekers are willing to accept relatively low returns to obtain jobs [5].

Classical theory attempts to discuss gender discrimination based on wage differentials. Due to women's congenital physical weakness and multi-factors, women's members are generally low in education. The traditional concept of society is based on the above reasons. Women's labor productivity is generally lower than that of men. Most industries are not suitable for female practitioners. "It is also understandable. But Fawcett (1918) does not agree with the view that women's labor productivity is low. She first proposed the theory of equal pay for equal work for men and women. The essence of the theory of equal pay for equal work is to ensure that female employees and male employees have equal opportunities for employment. In the process of hiring employees, business owners should first pay attention to whether the personal ability of job seekers meets the company's expectations rather than first eliminating female job seekers by gender. Edgeworth (1922) and Fawcett put forward the crowding hypothesis. They think that the main reason why female employees and male employees do the same job but their salaries are lower than male employees is that female job seekers are restricted to a relative in the career selection process. A narrower range. Florence (1931) proposed [6] that wage differences between genders have little to do with productivity. Mainly because female employees need to assume family responsibilities at the same time, making them lack of advantages in the labor market competition. At the same time, male workers in some industries do not accept the opposite sex. Moreover, male 
staff members have a certain rejection of accepting female leadership. Second, when evaluating professional pay, people tend to refer to same-sex pay rather than the opposite sex. The main reason for the low female professional salary is that the reference group salary has a certain impact on its expected salary, and the expected salary will affect its willingness to accept the existing salary. It is precisely because male occupations have different reference targets for female occupations, which ultimately leads to differences in their salaries [7].

Human capital theory was first proposed by Schultz and Becker in the 1970s. They believe that material capital and human capital are two manifestations of capital. Schultz and Becker also pointed out that due to differences in lifestyles, there is a significant difference in the investment of men and women in human capital. Women's family responsibilities include not only limited cumbersome housework, caring for young children and elderly people. Therefore, women's investment in their own human resources is staged. Correspondingly, since the employment process of men is basically non-disruptive, the investment of men in their own human resources is continuous, and there is basically no discontinuity. Because of this, in the process of hiring staff, business owners are more inclined to male job seekers and refuse female job seekers. Because male job seekers' investment in their human resource costs is more in line with corporate expectations [8].

Belk pioneered the theory of personal prejudice discrimination. The theory of personal prejudice is simply that employers will give different salary compensation to different employees because of their own likes and dislikes. The reason for this difference is simply that the business owner's own personal preferences are related to the employee's work skills and personal literacy. Of course, the reason for the business owner is to pay for their own preferences, which is understandable. For example, if a male business owner has a subjective bias against a female job seeker, then even if the female job seeker's ability to work is outstanding, it is in line with the job expectation. However, due to the subjective likes and dislikes of business owners, female job seekers will still not be employed. Unless a female job seeker is willing to self-depreciate to offset the employer's prejudice against women, it is possible for the business owner to hire a female job seeker [9]. At the same time, in some industries, there are discriminations caused by people's inherent beliefs. For example, some male employees are unwilling to accept female leadership, even if they are qualified for leadership work. For example, doctors, engineers, and drivers are more inclined to accept male employees, while nurses, teachers, and salespersons are more 
inclined to female employees.

Cecilia L. Ridegeway of Stanford University puts forward the "interaction theory" based on the research of men and women in job search and salary inequality [9]. Professor Li Weiwei said that employees have direct or indirect interactions in all aspects of their careers. In this process, people will involuntarily use gender cognition as the premise of communication. Upon receiving the influence of intrinsic gender thinking, people will have different behavior expectations for their partners according to their gender. In general, it is believed that men are superior to women in all aspects. Many working men will do better than women [10]. Influenced by the inherent concept of society, many women also think that men are better. Eventually, the phenomenon of "different pay for equal work" between men and women is widespread.

Related studies have shown that more and more women are on the job in recent years, but the phenomenon of gender discrimination in specific industry-specific positions has increased. The most prominent problem is the gender segregation in the profession in the industry [11]. The gender segregation theory of the labor market believes that the labor market is divided into male labor market and female labor market according to gender. Gender segregation has produced socalled "male jobs" and "female jobs". There are also scholars who blame women for their own causes of gender discrimination in employment. For example, women's physical fitness is inherently weaker than men, women's own low quality, and weak workplace competitiveness. The most important of these is the impact of female reproductive responsibility on the efficiency of female employees. Some scholars have pointed out that [12] women's weakness in the competition with men's workplace is that they need to experience the birth process more than once. In the process of pregnancy production and feeding, the business owner has to bear additional costs [13] [14]. In today's highly developed market economy, business owners will give priority to hiring male job seekers in the pursuit of maximizing their own interests.

\section{Research Ideas and Methods}

\subsection{Research ideas}

This study is mainly based on the Rahim Yar Khan region of Pakistan. Through interviews with local women, the survey results are analyzed and discussed. On this basis, the issue of employment gender discrimination in Pakistani professional women is explored. The quality of employment of female staff directly affects the quality of life affecting women's living conditions. 
The issue of gender discrimination in women's employment in the Islamic world is a special social problem that almost everyone knows but is closely related to research and almost blank. The author is deeply touched by a woman from the Rahim Yar Khan region of Pakistan. Therefore, the main reason for choosing professional women in the The Rahim Yar Khan area is that gender discrimination in employment in women in the current Pakistani workplace has severely restricted the employment of local women. For local female staff, it has become common practice to encounter employment gender discrimination in their employment. In the long run, it will inevitably lead to serious social problems, and it will also be unfavorable to the Pakistani labor market. In order to help Pakistan solve the problem of gender discrimination in women's employment, we have the idea of carrying out this research.

Therefore, the author puts forward specific research ideas and research contents based on literature research and his own experience. First-hand information is obtained through field surveys. Based on the analysis and discussion of the survey data and the previous research, the paper further analyzes the causes of gender discrimination in Pakistan and proposes specific solutions based on the knowledge.

First, collect information, clarify the research status of the topic and the latest developments in related research at home and abroad. Complete the syllabus and opening report.

Secondly, further collect the required data, including questionnaires, online public data, published literature data, and related research reports. The resulting data was analyzed and compiled to arrive at the results.

Again, in-depth analysis and discussion of the above conclusions to improve the results. And based on this, the first draft of the paper was completed.

Finally, under the guidance of the teacher, the article was revised repeatedly and the graduation thesis was finally completed.

\subsection{Research methods}

As a woman from the Rahim Yar Khan region of Pakistan, the author has an in-depth understanding of the gender discrimination in employment in women in the Rahim Yar Khan region of Pakistan. After entering Nankai University, systematically study the theory and research methods of anthropology. In this research process, the research methods such as the literature 
research method, the questionnaire survey method, and the case analysis method have been mainly used. In the actual research process, based on the analysis of relevant literature, the framework and main content of this paper are formed, and the relevant statistical data are analyzed by qualitative research methods, and finally form this paper.

The first is the use of literature analysis, collecting relevant literature is the basis of this study. In the early stage of the research, the public documents, data and other materials were obtained through the library, HowNet, Google Scholar, and the Federal Statistical Office of Pakistan. At the same time, attention is paid to relevant research on gender discrimination in women's employment.

Secondly, the questionnaire survey method, because the author is currently studying in China, therefore, only through the online questionnaire and at the same time with the help of local friends and relatives to obtain first-hand information in the Rahim Yar Khan region. This is also the focus of this study.

Finally, the case analysis method is based on the professional analysis of the employment gender discrimination cases that have occurred, so as to get a deeper understanding of related issues.

\section{Research Significance}

Theoretical significance: Regarding the study of gender discrimination, most scholars still start to conduct specific analysis and discussion based on the local legal system or economic basis. There is relatively little research based on the point of entry from the perspective of religion and sociology. I am from Pakistan, and I can see the shadow of Islam in all aspects of my country. The influence of religious culture on our daily lives is everywhere, and research on gender discrimination in professional women in the Islamic world is extremely rare. Therefore, the Rahim Yar Khan region is selected to explore the issue of gender discrimination among professional women, hoping to become a supplement to the gender discrimination research of professional women, and also to help follow-up research.

Practical significance: Sex discrimination against women in Pakistan has a long history. Along with the rapid development of Pakistan's domestic economy, more and more women are leaving the family to take up jobs. Correspondingly, gender discrimination in employment for female employees has become more serious. This seriously restricts women's power to obtain necessary production and living materials, and also affects women's self-life value. In this way, the 
issue of occupational discrimination against women is no longer a matter of pure moral cultivation, but a serious social problem. Even if there are laws that guarantee women's fair employment, sex discrimination against working women may violate the law.

Pakistan's domestic economic development level is relatively backward, and women's important labor resources have a role to play in promoting national economic growth. At the same time, women also assume the responsibility of nurturing the next generation. The next generation is the hope of the future of the country. Therefore, it is the responsibility of the state and the responsibility of the society to ensure that the legitimate rights and interests of female job seekers are not infringed and that women's employment equity is guaranteed. This has important practical significance for promoting the prosperity of the Pakistani state.

\section{2- Overview of the Rahim Yar Khan region of Pakistan}

\section{Overview of the Rahim Yar Khan area}

Rahim Yar Khan, located in the southeastern part of Punjab, Pakistan, in the northeast of Sukur. The total population of 4.81 million (2017) urban and rural population ratio of 2:8. The total area of the district is 11,880 square kilometers. The area includes four townships, namely Rahim Yar Khan, Sadiqabad, Liaquatpur and Khanpur. The main industries in the region include fertilizer, cosmetics, glass manufacturing, cotton production and processing, large-scale textile equipment, flour mills, sugar oil plants and large-scale power generation projects. Food crops are dominated by wheat and rice, and cotton is the main cash crop. Mango and orange are the two main types of water in the city [15] [16].

The province with the most developed industries and industries in Pakistan is Punjab. According to statistics, $90 \%$ of paper, $80 \%$ of grain, $75 \%$ of fertilizer, $70 \%$ of sugar and $40 \%$ of cement in Pakistan are produced in Punjab [17][18]. In addition, Punjab is also the only province in Pakistan that has achieved county-level highways. The Rahim Yar Khan region is another industrial and commercial gathering center in the Punjab province [20]. The extensive railways and intensive air routes in the region make Rahim Yar Khan closely connected with other industrial centers in China such as Lahore, Karachi and Quetta, and even connect to developed regions of India. The Rahim Yar Khan region has convenient transportation, a large population, and the total industrial and agricultural output value ranks among the top in the country. Then there will be a large-scale labor market in the local area. The enterprise is not a welfare institution, and the 
ultimate goal of the business owner is to maximize the benefits. Then it is not surprising that there is employment in gender discrimination.

\section{3- Innovation and Insufficiency}

1. First, research topic innovation. The subject of this paper is the issue of gender discrimination in professional women in Pakistan. In general, research in Pakistan focuses on politics, economics, and religious culture. Research on gender discrimination involving professional women is basically a "labor vacuum" stage. There are few published research results and lack of systematic research results.

2. Second, research data innovation. This article examines relevant literature at home and abroad, as well as public data from the Rahim Yar Khan region. And with the help of local friends to complete the questionnaire survey, the gender discrimination data of professional women in the Rahim Yar Khan region of Pakistan was updated to make up for the delay in updating the relevant research data.

3. Finally, research perspective innovation. This paper attempts to analyze the gender discrimination of professional women in Pakistan by combining the Western countries and China's systematic anti-sex discrimination theory. And draw on its mature experience of improving gender discrimination in women to apply to Pakistan's work against gender discrimination in employment.

Because the study of gender discrimination in Pakistan is basically a blank, related research is inevitable. Due to objective conditions, there is a certain lag in published data. Field investigations are not possible in Pakistan, so only the Pakistani Rashim Yar Khan area was selected as the research object. Data samples may be less representative, and too few data samples may affect the conclusions. I look forward to the opportunity to conduct more in-depth and comprehensive investigations in the future in order to obtain more data for further and more systematic research.

\section{4- Questionnaire Results}

In the actual investigation process, the questionnaire is first prepared (Appendix 1). The questionnaire covers various gender discrimination issues that women employees may encounter in all aspects of employment, such as entry barriers in the recruitment process; discrimination in 
the process of job assignment; equal pay for men and women in the payroll process; and artificial various obstacles set. With the help of relatives and friends in the Rahim Yar Khan region of Pakistan, the questionnaires were randomly distributed to local female staff. After they completed the questionnaire, they collected the questionnaires and collated them in order to obtain relevant data for further analysis and discussion. In this survey, 100 questionnaires were distributed, 100 copies were collected, and 98 valid questionnaires were obtained through collation. The main contents of the questionnaire included the age distribution of female staff in the Rahim Yar Khan region of Pakistan, the distribution of the industry, the distribution of education, the distribution of monthly income and the incentives for local female employees to encounter gender discrimination in employment.

Section 1 Age distribution of female staff in the Rahim Yar Khan region of Pakistan

Organizing the questionnaire to obtain the age distribution of female staff in the Rahim Yar Khan region of Pakistan is shown in the table below.

Table 1 Age distribution of female staff in the Rahim Yar Khan region of Pakistan

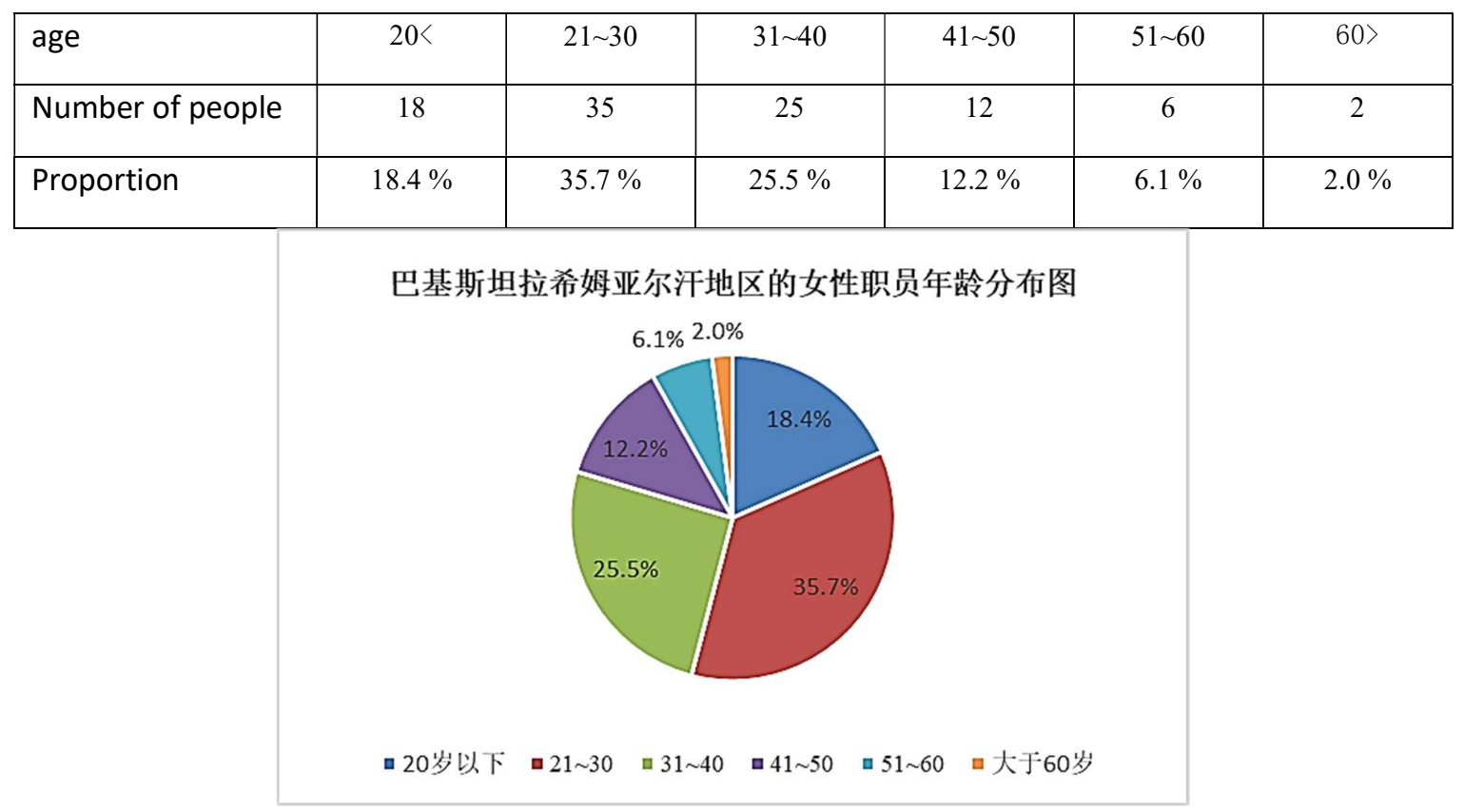

Figure 1 Age distribution of female staff in the Rahim Yar Khan region of Pakistan

From the chart (Table 1, Figure 1), it can be seen intuitively that the age distribution of female staff in the Rahim Yar Khan region of Pakistan is mainly concentrated in the stage of 20 to 40 years 
old (61.2\%), which is also the most energetic of a natural person. During the period, the number of women over forty years of age was significantly reduced, which may be caused by the need to raise children or family factors that led to women's occupations leaving the job.

Section 2 Female staff in the Rahim Yar Khan region of Pakistan is mainly engaged in the industry distribution

Table 2 Female staff in the Rahim Yar Khan region of Pakistan is mainly engaged in the industry distribution table

\begin{tabular}{|l|c|c|c|c|c|}
\hline Post & Freelancers & $\begin{array}{c}\text { Service and } \\
\text { sales people }\end{array}$ & Craftsmen & $\begin{array}{c}\text { Education } \\
\text { industry }\end{array}$ & 0ther \\
\hline Number of people & 13 & 21 & 48 & 6 & 10 \\
\hline Proportion & $13.3 \%$ & $21.4 \%$ & $49.0 \%$ & $6.1 \%$ & $10.2 \%$ \\
\hline
\end{tabular}

巴基斯坦拉希姆亚尔汗地区的女性职员主要从事行业分布图

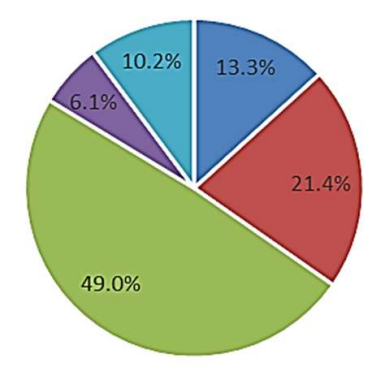

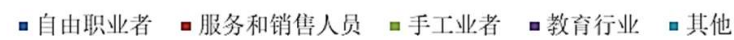

Figure 2 Female employees in the Rahim Yar Khan region of Pakistan are mainly engaged in the distribution of industry

The chart (Table 2, Figure 2) reflects that the female employees in the Rahim Yar Khan region of Pakistan are mainly based on simple labor such as handicraft industry (49.0\%), sales service industry $(21.4 \%)$, and freelance (13.3\%). The above-mentioned industries have low barriers to entry, low salary levels, and employment security in most industries.

Section III Distribution of education among female staff in the Rahim Yar Khan region of Pakistan

At the same time, the educational level of the female employees interviewed was investigated. The results are shown in the following chart (Table 3, Figure 3).

Table 3 Distribution of educational attainment of female staff in the Rahim Yar Khan region of Pakistan 


\begin{tabular}{|l|c|c|c|c|c|c|}
\hline Age & $\begin{array}{c}\text { Under the } \\
\text { elementary } \\
\text { school }\end{array}$ & $\begin{array}{c}\text { junior } \\
\text { high } \\
\text { school }\end{array}$ & $\begin{array}{c}\text { high } \\
\text { school }\end{array}$ & $\begin{array}{c}\text { universit } \\
\text { y }\end{array}$ & $\begin{array}{c}\text { master' s } \\
\text { degree }\end{array}$ & $\begin{array}{c}\text { master's degree or } \\
\text { above }\end{array}$ \\
\hline Number of people & 19 & 27 & 24 & 15 & 11 & 2 \\
\hline proportion & $19.4 \%$ & $27.6 \%$ & $24.5 \%$ & $15.3 \%$ & $11.2 \%$ & $2.0 \%$ \\
\hline
\end{tabular}

巴基斯坦拉希姆亚尔汗地区的女性职员受教育程度 分布图

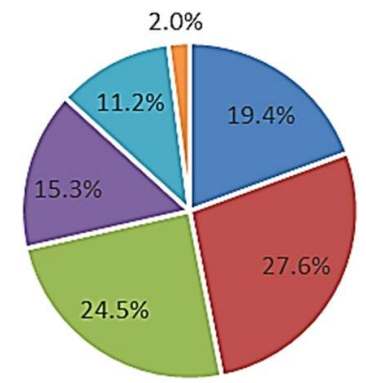

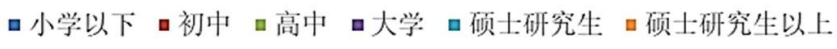

Figure 3 Distribution of educational attainment of female staff in the Rahim Yar Khan region of Pakistan

According to the data released by the Federal Statistical Office of Pakistan (http://www.pbs.gov.pk), as of the end of 2018, more than $42.6 \%$ of Punjab women were illiterate. The survey used questionnaires, so respondents had an education experience, but $19.4 \%$ of the respondents still had a level of education below primary school, and only about $28.6 \%$ of the respondents had higher education.

Section IV Distribution of monthly income of female staff in the Rahim Yar Khan region of Pakistan

The author also conducted an investigation into the income of the respondents. The results are as follows:

Table 4 Monthly income distribution of female staff in the Rahim Yar Khan region of Pakistan

\begin{tabular}{|l|c|c|c|c|}
\hline income & $\begin{array}{c}\text { Less than } \\
5000\end{array}$ & $5001 \sim 10000$ years & $10001 \sim 15000$ years & more than 15000 \\
\hline Number of people & 57 & 21 & 12 & 8 \\
\hline proportion & $58.2 \%$ & $21.4 \%$ & $12.2 \%$ & $8.2 \%$ \\
\hline
\end{tabular}




\section{巴基斯坦拉希姆亚尔汗地区的女性职员收入分布图}

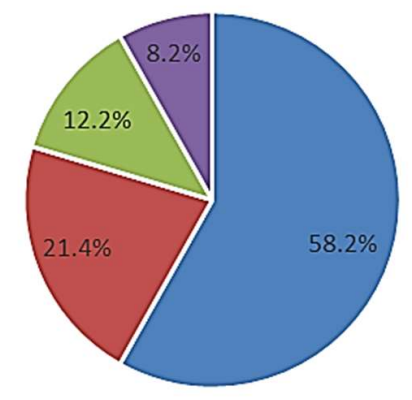



Figure 4 Distribution of female staff income in the Rahim Yar Khan region of Pakistan

The chart (Table 4, Figure 4) reflects the income distribution of female staff in the Rahim Yar Khan region of Pakistan. It can be clearly seen that approximately $91.8 \%$ of respondents earn less than 15,000 rupees per month (about 945 renminbi. Only 8.2\% of respondents earn more than 15,000 rupees. According to the Federal Statistical Office of Pakistan (http:/ /www.pbs.gov.pk) By the end of 2018, nearly 50\% of male employees in Punjab had incomes of more than Rs. 15,000. Female employees had relatively low incomes and that female employees were low-educated and could only engage in low-level work. It is closely related.

Section V Female staff in the Rahim Yar Khan Region of Pakistan suffers from gender discrimination in employment

Through the compilation of 98 valid questionnaires, the author found that almost all female employees have encountered or are experiencing gender discrimination in their careers. The following two tables list the stages of gender discrimination in local female employees and how they are dealt with after gender discrimination.

Table 5 Female staff in the Rahim Yar Khan region of Pakistan encounters a stage of gender discrimination

\begin{tabular}{|l|c|c|c|c|}
\hline stage & Job search & position & salary & promotion \\
\hline Number of people & 88 & 75 & 94 & 89 \\
\hline proportion & $89.8 \%$ & $76.5 \%$ & $95.9 \%$ & $90.8 \%$ \\
\hline
\end{tabular}

Table 6 Treatment of female employees in the Rahim Yar Khan region of Pakistan after encountering gender discrimination 


\begin{tabular}{|l|c|c|c|c|}
\hline $\begin{array}{l}\text { Number } \\
\text { of people }\end{array}$ & $\begin{array}{c}\text { Reluctantly } \\
\text { accepting }\end{array}$ & $\begin{array}{c}\text { Controversy with } \\
\text { the unit. }\end{array}$ & $\begin{array}{c}\text { Complaints to the } \\
\text { relevant } \\
\text { departments }\end{array}$ & other \\
\hline $\begin{array}{l}\text { proportio } \\
\mathrm{n}\end{array}$ & 72 & 15 & 8 & 3 \\
\hline $\begin{array}{l}\text { Number } \\
\text { of people }\end{array}$ & $73.5 \%$ & $15.3 \%$ & $8.2 \%$ & $3.1 \%$ \\
\hline
\end{tabular}

By analyzing the above data, the author finds that the gender discrimination in employment experienced by female employees in the Rahim Yar Khan region of Pakistan is almost full of their entire career. Among them, $95.9 \%$ of respondents believe that they face gender discrimination in terms of salary. The main performance is that the male and female employees are paid differently, and the company will reduce the salary during pregnancy. Eighty-eight percent of the respondents indicated that they encountered gender discrimination in the job search process. The specific performance is that the company is more willing to hire male job seekers during the recruitment stage, and the company is unwilling to hire women of childbearing age. The gender discrimination in the promotion stage for female employees is specifically shown as high salary, and the number of female employees in management positions is significantly less; whether male employees are more likely to obtain promotion opportunities than female employees. Sex discrimination is manifested in the job allocation stage, and some positions do not allow female staff to participate. At the same time, respondents suggested that, for example, in the process of signing an employment contract, the company requires female employees to declare that they are not pregnant within a few years of work, and the unemployment rate of female employees is generally higher than that of men.

After the local female staff encountered the problem of gender discrimination in employment, $73.5 \%$ of the respondents indicated that they would choose to accept and suffocate; about $15.3 \%$ of the respondents would choose to compete with the unit; only $8.2 \%$ of the respondents It said that it would choose to take legal weapons to defend its legitimate rights and interests, mainly due to the weak legal awareness of local female employees. At the same time, excessive cost of rights protection is also one of the important reasons why female employees have to swallow their rights when their legal rights are violated. In this way, it is also very important to reflect the unsound legal system against discrimination in employment in Pakistan. Almost all of the respondents said 
that Pakistan should immediately enact a special Anti-Employment Discrimination Act and set up a special women's rights protection institution to protect women's legitimate rights and interests from infringement.

Table 7 Female staff in the Rahim Yar Khan region of Pakistan suffers from gender discrimination in employment

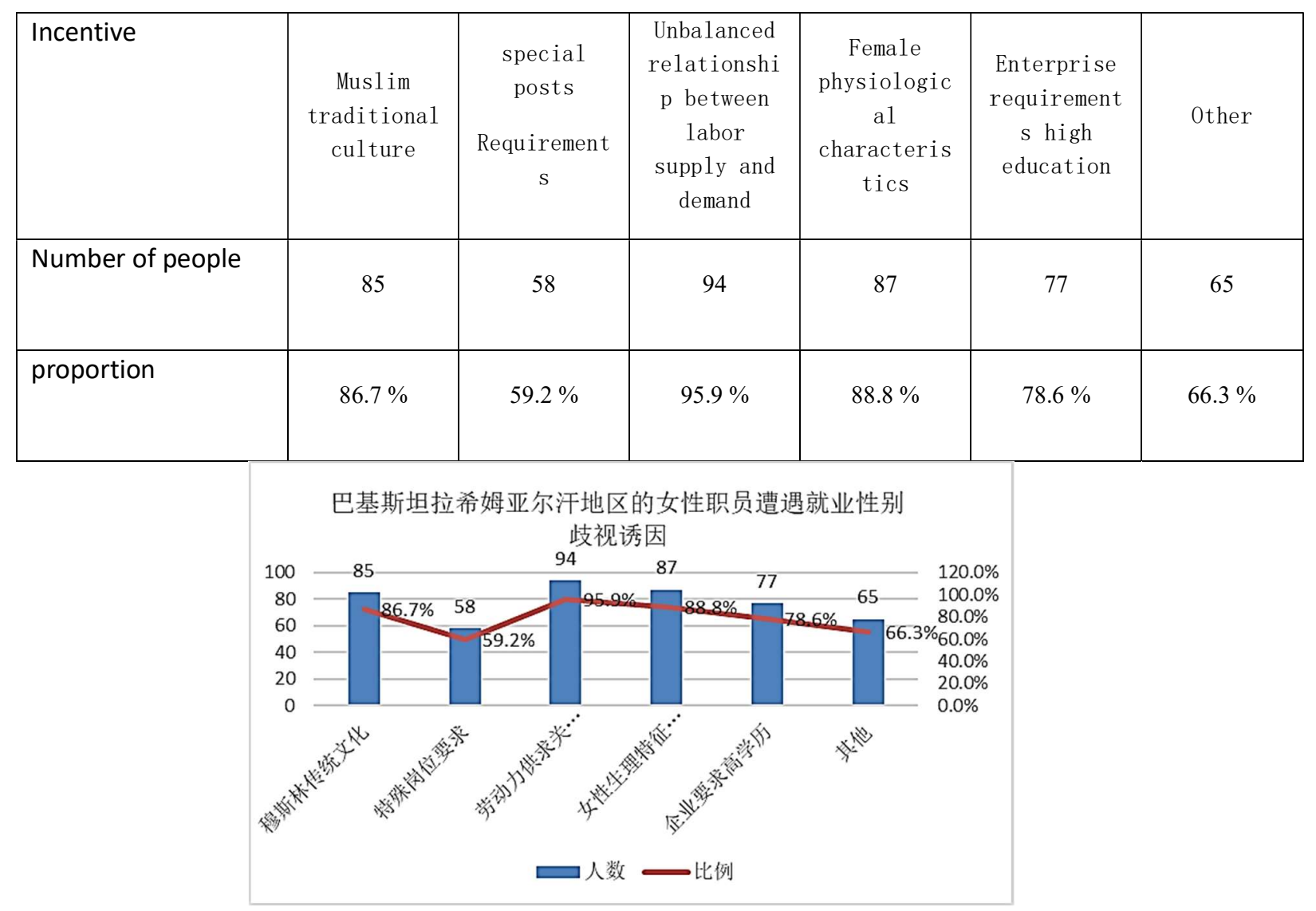

Figure 5 Female staff in the Rahim Yar Khan region of Pakistan suffers from gender discrimination in employment

More than $95.9 \%$ of the women surveyed believe that the imbalance between labor supply and demand is the primary factor that causes female employees in the Rahim Yar Khan region of Pakistan to encounter gender discrimination in employment. This is followed by women's own physiological characteristics $(88.8 \%)$ and Muslim traditional culture (86.7\%).

\section{Section VI Summary of this chapter}

This section focuses on the survey data after sorting out the collected questionnaires. It is mainly aimed at the employment status of the respondents and the investigation of the problem of gender discrimination in employment. The data obtained provide data support for relevant research and belong to one of the key chapters of the full text. 


\section{5- Data Analysis and Results Discussion}

Through the analysis of the data obtained from the questionnaire, the author found that the female employees in the Rahim Yar Khan region of Pakistan experienced more serious employment discrimination than the public reports. The following will be based on the data obtained from the questionnaire to conduct a specific study on the gender discrimination in employment experienced by female employees in the Pakistan Rahim Yar Khan region.

\section{Section 1 Inducement of gender discrimination in employment of female staff in Rahim Yar Khan, Pakistan}

As a typical Muslim country, Pakistan has a gender discrimination against women. In recent years, with the steady development of Pakistan's domestic economy, more and more housewives have gradually stepped out of their homes and started to participate in social work like men. The resulting local women's encountering gender discrimination in the employment process has gradually become a high-profile social problem. The results of this survey can also support this view. Almost all respondents have clearly stated that they have encountered or are experiencing gender discrimination in their job search or daily work. There are many reasons for this problem. This is partly due to the traditional Muslim culture in Pakistan and to the imbalance between the supply and demand of local labor. At the same time, the local women's own quality is not negligible. The quality mentioned here includes both female physical quality and female educational literacy [21] [22]. The following is a detailed analysis of the incentives for the employment of female employees in the Rahim Yar Khan region of Pakistan based on the survey data and the existing research results.

\subsubsection{Unbalanced labor supply and demand relationship}

The imbalance between labor supply and demand is the first incentive for many respondents to think that local female employees are facing gender discrimination in employment. According to the latest data released by the Federal Statistical Office of Pakistan (http://www.pbs.gov.pk), the results of the most recent census in 2017 indicate that the total number of people in Pakistan exceeds 207 million, ranking sixth in the world. Punjab has a population of about 110 million, accounting for about $53 \%$ of the country's total population. The total population of the Rahim Yar Khan region is about 4.81 million. Compared with the fifth census in 1988, it increased by about $50 \%$, and the average annual growth rate of the population was $2.4 \%$. Since there is no similar 
family planning policy, the total population and age-appropriate labor force in the Rahim Yar Khan Region is still on the rise. It is expected that the labor force in the Rahim Yar Khan region will continue to grow for a long time in the future. . This is fortunate for business owners because they can get quality employees at a lower salary. But for job seekers, the situation is bad because they not only face increasingly fierce competition, but they are not guaranteed to get the right rewards [26].

The problems caused by the continuous increase in labor force are obvious. One is the surplus of labor resources; the other is that the number of job supply will decrease year by year. First of all, the imbalance between labor supply and demand is undoubtedly a nightmare for practitioners. And this is even less friendly to female staff. Once the business owner needs to abolish some of the staff, then female employees are often the first to be abolished. The legitimate interests of female employees cannot be guaranteed, which inevitably makes the situation of female employees in the workplace more serious. Secondly, the influx of labor into the workplace will inevitably lead to frequent unemployment problems. Data show that (http://www.pbs.gov.pk) Punjab unemployment rate is $5.97 \%$, including male unemployment rate of 5.39\%, female unemployment rate of $7.45 \%$; urban female unemployment rate of $14.92 \%$. When the jobs that the labor market can provide cannot meet the needs of job seekers, it will inevitably lead to increasingly fierce job competition. The fierce post has made it impossible to talk about equality in employment between the sexes. The most intuitive manifestation of this imbalance is that the quality and quantity of female employees in the workplace is significantly weaker than that of men. The reason for this problem is caused by the imbalance between supply and demand in the Pakistani labor market. The most direct manifestation of labor imbalance in the workplace is that companies set different thresholds in the recruitment process and exclude women. To put it simply, when a department needs to hire 1 staff member, more than 10 applicants come to apply. In order to maximize the benefits of enterprises, and to be influenced by traditional concepts, business owners believe that women's work efficiency is generally lower than that of men, and women's job seekers will inevitably be rejected first. Even for some jobs that require a large number of women, such as nurses, nurses, waiters, etc., if there are a large number of job seekers in the labor market to choose from, they often impose restrictions on female job seekers in order to maximize their benefits. The financial crisis has led to a slowdown in global economic growth. Pakistan's domestic economy is sluggish due to wrong economic policies, a large number of people are unemployed, and existing occupational employment pressures are increasing day by day, and domestic social conflicts are 
intensifying. In order to alleviate this contradiction, it has been proposed to let female employees return to their families and give up their positions to men, so the contradictions are solved. In my opinion, this is a very serious view of gender discrimination. In the old society, women were often seen as vassals of men. But now it is already in the 21 st century, and equality between men and women is definitely not just a slogan.

\subsubsection{Female's own physiological characteristics}

In the workplace of the Rahim Yar Khan region, women's own physiological characteristics are one of the important reasons for their employment gender discrimination. The physiological differences between men and women are a special cause of women's employment [30][32]. The differences in physiological characteristics between the two sexes are mainly reflected in the differences in physical strength between men and women. Big data research shows that there is almost no intellectual difference between men and women, and even some women have better IQ than men. But the widely accepted view of the people is that women are generally physically weaker than men in terms of physical strength. At the same time, for some high-intensity continuous labor, men are significantly better than women. Therefore, in some positions that value the physical strength of job seekers, men will be preferred. Women are mainly engaged in industries that do not rely on heavy physical labor. Since the industrial revolution, science and technology have developed rapidly, and the importance of physical differences has gradually weakened in the workplace, but its influence is still there. The domestic modernization process in Pakistan is relatively slow. The main industries in the Rahim Yar Khan region include fertilizer, glass manufacturing, cotton production and processing, large-scale textile equipment, and largescale power generation projects. Relevant industries still have certain requirements for the physical fitness of practitioners. In the above-mentioned industries, male employees have more advantages than women. Therefore, companies will give priority to male job seekers.

\subsubsection{Muslim traditional culture}

Pakistan is a typical Islamic country, and the Muslim style is reflected in all aspects of society, as is the case in the Rahim Yar Khan region. After thousands of years of development, Muslim culture has long been integrated into the blood of local people, and the influence of this culture will gradually deepen with the inheritance of history. It is precisely because of this ubiquitous Muslim culture that people will unwittingly follow this cultural tradition in their daily lives and work. Influenced by the traditional Muslim concept, Pakistan has a strong trace of patriarchal 
society. In many local situations, male members are absolutely dominant in both social and family life, and women are more dependent on men. This is not only the case in the old society, but it is still widely accepted by the local people with its strong historical inertia in the 21 st century. In the Rahim Yar Khan region, whether in the city or in the countryside, in most cases, the main job of women is to "make a child" at home, unless they are in some higher-ranking families or divorced women, they are free to control their own life.

In Pakistan's traditional concept, men mainly assume social responsibility, while women are attributed to the family. Therefore, women under the traditional concept will be positioned as the role of "good wife and good mother" and "family care". This traditional gender division of labor makes women tend to choose lower occupations. Under the influence of traditional concepts, from a business perspective, women are considered to be more suitable for a relaxed and simple career, which in turn leads some companies in certain industries to consciously exclude women from the workforce during the recruitment process, or in the distribution of gender discrimination, important positions or senior positions are preferred for male employees.

From a female perspective, many women tend to engage in relaxed, flexible careers such as services, teachers, and salespeople when choosing jobs. Under the influence of patriarchal concepts and institutions, women first consider the family when entering the labor market, and men first consider how to get a high-income job to support their families.

\subsubsection{Enterprise requirements for academic qualifications}

Seventy-seven percent of respondents believe that a company's requirement for academic qualifications is one of the key factors that lead to gender discrimination in employment. This also reflects the need to improve the level of female education in Pakistan. According to the survey data, less than $28.5 \%$ of the respondents had college education, and nearly half of them did not enter high school.

There are public reports that women in the Rahim Yar Khan region are generally undereducated. A large number of local women are illiterate or semi-literate. The enrolment ratio of children of both sexes is also much higher for boys than for girls, especially in the vast rural areas. A large number of women have never received school education for the rest of their lives. It is hard to believe that there are still a large number of people who do not recognize words in the $21 \mathrm{st}$ century. Today's social science and technology is developing rapidly, and new industries and new 
jobs are placing higher demands on practitioners. But these illiterate or semi-literate women are clearly not considered, and it is almost impossible for them to quickly master the latest technologies and skills to adapt to the development of the industry. The reason is that the author believes that this is mainly because the local society and family in Pakistan have low expectations for women and are unwilling to provide a large amount of investment in education for women [31].

In the new century, as the society continues to advance, in order to protect the company's further development and growth, business owners are more inclined to hire employees with higher cultural level and skilled labor skills. Due to the large rural population in the Rahim Yar Khan region, the overall level of local women's cultural level is generally low. This is one of the most important reasons for restricting the participation of local women in social work. It is also the female staff who are competing with the male workplace. The most fundamental cause of the disadvantage. Secondly, influenced by local Muslim culture and social traditions, society and families are reluctant to provide too much investment in education for female members. As a result, the overall cultural literacy of female members is generally lower than that of males. Affected by traditional concepts, most women have already accepted this reality. Women under the influence of this concept are generally lacking in enterprising spirit. At the same time, most of them choose passive acceptance when their legal rights are violated. Therefore, local business owners will directly reject female job seekers or give female employees lower salary during the recruitment process. In the workplace of the Rahim Yar Khan region, women's own quality is a key factor in determining the size of their workplace competitiveness. Due to the lack of education and low cultural quality, it is excluded from the workplace. This is both the sorrow of women themselves and the sorrow of society [33].

\subsubsection{Insufficient laws and regulations}

Almost all of the respondents indicated that Pakistan needs to improve the domestic antidiscrimination legal system as soon as possible. The government should give women a clear guarantee of employment rights in terms of legislation and law enforcement [29].

After entering a new era, Pakistan's domestic economic structure has undergone major changes, and labor relations have become more diversified and complicated. However, relevant laws and regulations concerning labor security in Pakistan have been issued earlier, and some legal provisions are not applicable to the current economic situation. In today's Pakistani workplace, women's employment pressures are unprecedentedly large, and the gender discrimination problem 
they face is even more serious. At the same time, existing labor laws and regulations cannot play their due role in protecting the legitimate rights and interests of female workers. The existing legal system has a certain effect on eliminating gender discrimination in women's employment, but it still has defects and needs to be improved.

The domestic labor supply and demand relationship in Pakistan has changed with the changes in the economic system. The existing domestic legal system has become incapable of protecting the legitimate labor rights of female job seekers. Therefore, it is particularly important to reform the existing anti-discrimination legal system as soon as possible and to promulgate a legal system that guarantees the legitimate rights and interests of female job seekers in line with Pakistan's basic national conditions. Due to the premature promulgation of the current labor law and regulation system in Pakistan, some provisions have not met the current domestic labor market in Pakistan. Relevant laws and regulations are not clear about the criteria for determining gender discrimination in women. Therefore, the primary task of improving discrimination against female employment in Pakistan is to clarify the definition of gender discrimination in women, especially to explicitly define some invisible discrimination or more subtle gender discrimination, thereby enhancing the operational system of anti-sex discrimination laws and regulations. Sex.

Secondly, law enforcement efforts and the supervision of relevant departments need to be improved in the specific implementation process of relevant laws. In recent years, Pakistan's domestic labor inspection departments have focused on the protection of female employees' labor equity rights mainly in terms of salary and women's rights. There is less concern about the invisible gender discrimination of female employees in the recruitment process and promotion space of business owners. At the same time, the supervision of women's gender discrimination in Pakistan's domestic labor inspection department is lagging supervision. In most cases, after the female staff encounters the problem of gender discrimination in employment, the relevant departments will take action, which has little effect on eliminating the problem of gender discrimination in women's employment in Pakistan. The laziness of government departments and labor inspection departments will eventually lead to the use of legal weapons to ensure that the equal labor rights of female employees can only be in the form. Therefore, relevant departments are required to earnestly fulfill their responsibilities, ensure that the anti-discrimination legal system can be smoothly implemented, and effectively protect the legitimate labor rights of female employees.

In recent years, Pakistan's domestic economy has grown at a faster rate, and it is not 
uncommon to infringe on the legitimate rights and interests of female employees in terms of employment opportunities, job promotion, salary compensation, labor protection and security. When female employees encounter employment gender discrimination in the workplace, most of them will choose to swallow their voices, and there are very few people who dare to take legal weapons to defend their legal rights. The illegal costs of business owners are almost negligible, and female employees whose legal rights have been infringed are either afraid to complain or have no complaints. On the one hand, it has fueled the arrogance of business owners, and on the other hand has hit the enthusiasm of female employees. In the long run, the problem of gender discrimination in the employment of female employees in Pakistan will inevitably become more serious.

In summary, Pakistan's domestic legal system against employment gender discrimination is not perfect, the existing laws and regulations lack effective supervision in the implementation process, and female staff members are not good at using legal weapons to protect their legitimate rights and interests because of the gender discrimination caused by Pakistani staff. The reason is.

\subsubsection{Missing social security system}

The social security system is mainly aimed at improving the issue of gender discrimination in employment. It is not just the dilemma faced by women in almost every part of Pakistan in their workplaces, the most important of which is the need for women to balance their children and work. Women need to stop working during childbirth and subsequent breastfeeding. However, the business owner still has to pay a certain salary to the female employees during this period, which is contrary to the business philosophy that the business owner pursues the maximum benefit. At the same time, there is no corresponding policy measures in Pakistan to share this part of the losses. Therefore, in the recruitment process, business owners will take the lead in eliminating the female job seekers who have the marriage and childbirth program in the past two years. This makes women's situation in the job search process more difficult. At the same time, it should be pointed out that most of the existing social security systems in Pakistan are some advocacy clauses, and the penalties for corporate violations need to be deepened. This leads to the company's cost of noncompliance is too low, and in the long run will inevitably lead to the flow of policies in the form of protection of women's rights and interests. This requires relevant departments to increase policy implementation in the later period, and at the same time increase the cost of corporate violations, and also implement relevant policies and measures to compensate for corporate losses and protect 
the interests of both enterprises and employees.

\subsubsection{Enterprises pursue maximum benefits}

The essence of the labor market is the capital market. The ultimate goal of business management is to maximize the benefits. The serious incentives for the employment of female employees in the Rahim Yar Khan region of Pakistan mentioned above are all due to the pursuit of maximum profits. Today's Pakistani society has more and more enterprises to regard the value of "Capital" in the "Capital" as a classic. Driven by the values in this, business owners always regard the pursuit of maximization of interests as their ultimate goal in their production and operation activities. Then in the first recruitment stage, the business owner first considers the "expected benefit cost" and "cost-benefit curve". I hope to get the highest return with the least amount of investment. After the business owner comprehensively compares the "indicator parameters" of male and female job seekers, it is obvious that male workers are more in line with corporate expectations.

For enterprises, the biggest difference between recruiting women and men is that women must experience the stage of marriage and childbirth in their future work, while enterprises need to bear the cost of job vacancies for female employees during pregnancy. Therefore, in order to pursue the most profitable business, the business owner must consider the employment of female employees. After weighing the benefits and costs, business owners will naturally choose to hire male employees and shut out female employees, which will make female employees obviously inferior in the workplace competition. This phenomenon is common in cities. In Punjab Province, for example, the urban female unemployment rate is as high as $14.09 \%$, and female employment is in a difficult situation. Fertility problems prevent female employees from working for a long period of time. For business owners, hiring female employees is subject to the loss of expected labor productivity. Secondly, with this "empty window period", women's work ability will be significantly reduced, leading to further weakening of the competitiveness of female employees. Moreover, most business owners believe that female employees' ability to adapt is generally weaker than that of men. In some industries with difficult working conditions, the compensation wages required to hire female employees are much higher than those of male employees. As a result, hiring male staff is clearly more in line with the expectations of business owners.

In economics, the cost of birth, the expected reduction in labor productivity, and compensatory wages are considered as "natural attachment costs". For companies, the additional 
cost of hiring female staff is higher. It can be foreseen that in the case of roughly the same labor cost, the employment of a large number of female job seekers will inevitably increase the labor cost of the enterprise, which is obviously not in line with the pursuit of profit maximization of the business owner, which also becomes the most direct rejection of female job seekers by business owners. Economic reasons.

At present, women's gender discrimination in employment is a natural choice for enterprises to maximize their interests. Under the existing social environment in Pakistan, the employment options offered by business owners for female job seekers are very limited, and most of them are labor-intensive jobs with cumbersome content, low technical content, low salary and almost no promotion. In these industries, there is basically no legal right to protect female employees. At the same time, in most cases, female employees also have to bear heavy family responsibilities, such as feeding young children and caring for the elderly. This will make it unnecessary for female staff to devote $100 \%$ of their energy to their work, objectively reducing the overall competitiveness of female employees. Business owners are considering this aspect in the recruitment process. Even in the case of the same objective conditions or even better job seekers, business owners will be more inclined to choose men and reject female job seekers. At the same time, when the company faces difficulties and needs to lay off personnel, female employees will generally be listed as the object of abolition first.

Pakistan is in the midst of a transition to a socio-economic model. Despite the continuous development of society, the information technology industry and high-tech industries provide more job options for female job seekers. However, due to the limited level of education, the high entry barriers in the high-tech industry block most female job seekers. At the same time, due to the constraints of the social environment, even if female employees enter the corresponding high-tech industries, their promotion prospects are very slim. There are few women in Pakistan who are in a leading position in the highly sophisticated industry, unless some particularly outstanding women are Benazir Bhutto. But some elite cases do not represent the situation of the vast majority of ordinary people. At the very least, the promotion of female staff in Pakistan is significantly more difficult than in men.

In recent years, influenced by the market economy thinking, the company's main ones pursue the maximization of benefits. The entire Pakistani society began to gradually "see the money." The "special service" that was cast aside in the early years began to flourish. In this type of industry, 
female employees are the trade itself, and their bodies are traded goods. Accompanied by the public's spit, embarrassment and attack on such women, this also deepens the society's "weakening" of female employees from another aspect.

\section{Section 2 Analysis of the Employment Status of Female Staff in Rahim Yar Khan Region, Pakistan}

According to the Federal Statistical Office of Pakistan (http://www.pbs.gov.pk), the data of the five censuses in the Rahim Yar Khan region are shown in Figure 6.

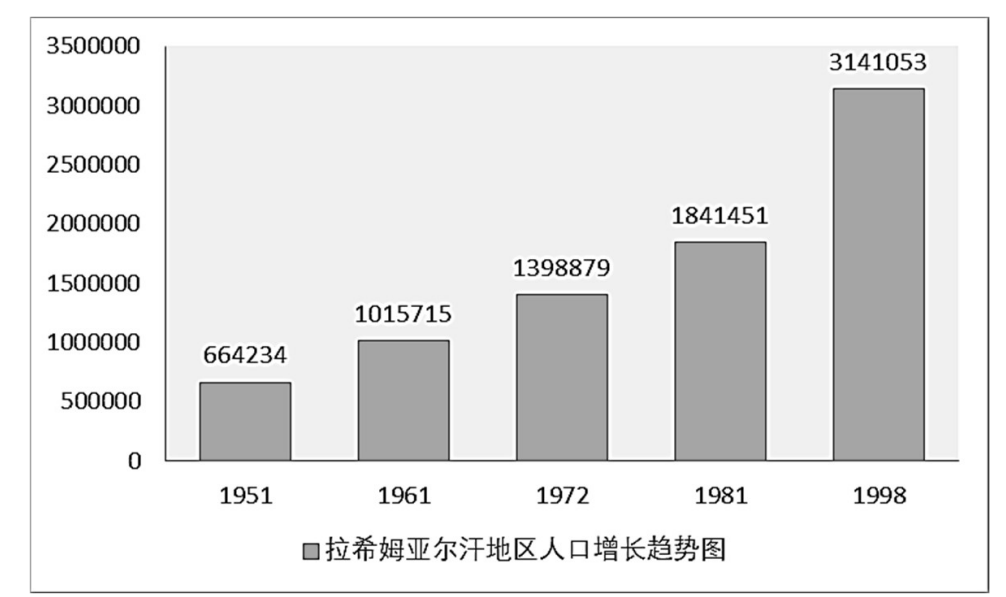

Figure 6 Population growth trend map of Rahim Yar Khan region, Pakistan

In 1998, the population of the city's census was $3,410,053$. The population growth rate between the 1981 and 1998 censuses was 3.19\%. The current trend is predicted. By 2020, the population is expected to be around 5.4 million. The rapid increase in population is one of the most fundamental reasons for the imbalance in the supply of local labor.

According to the data released by the Federal Statistical Office of Pakistan (http://www.pbs.gov.pk), by the end of 2018, the employment rate of women in Punjab is less than $30 \%$, even for women aged $30-40$ who are in the best working age. The rate is only about $35.7 \%$. Correspondingly, the local male employment rate of $20-40$ years old is over $85.7 \%$, and the employment rate of 30-40 years old is over $98 \%$. In the case of roughly the same ratio of men and women, the employment rate of women of the right age is significantly lower than that of men, which can clearly indicate that the problem of gender discrimination in employment of local women is severe.

The Federal Statistical Office of Pakistan (http://www.pbs.gov.pk) also publishes the 
distribution of gender employment in Pakistan's Punjab Province from 201 to 2018 (Table 8). Since the Rahim Yar Khan region does not have such detailed data, the use of Punjab data can also explain the problem.

Table 8 Distribution of gender employment in Pakistan Punjab Province from 2017 to 2018

\begin{tabular}{|c|c|c|c|c|c|c|c|c|c|}
\hline \multicolumn{10}{|c|}{$\begin{array}{l}\text { PERCENTAGE DISTRIBUTION OF EMPLOYED PERSONS } 10 \text { YEARS OF AGE AND OVER ENGAGED IN } \\
\text { INFORMAL SECTOR BY MAJOR OCCUPATION GROUPS, SEX AND AREA 2017-18 }\end{array}$} \\
\hline \multicolumn{10}{|l|}{ PUNJAB } \\
\hline \multirow{2}{*}{ Major Occupation Groups } & \multicolumn{3}{|c|}{ All areas } & \multicolumn{3}{|c|}{ Rural } & \multicolumn{3}{|c|}{ Urban } \\
\hline & Total & Male & Female & Total & Male & Female & Total & Male & Female \\
\hline TOTAL & 100.00 & 84.72 & 15.28 & 51.05 & 42.73 & 8.33 & 48.95 & 41.99 & 6.95 \\
\hline Managers & 2.47 & 2.40 & 0.07 & 0.63 & 0.58 & 0.05 & 1.84 & 1.82 & 0.02 \\
\hline Professionals & 3.90 & 2.38 & 1.52 & 1.72 & 1.12 & 0.59 & 2.18 & 1.25 & 0.93 \\
\hline $\begin{array}{l}\text { Technicians and Associate } \\
\text { Professionals }\end{array}$ & 3.89 & 3.72 & 0.17 & 1.63 & 1.55 & 0.08 & 2.25 & 2.16 & 0.09 \\
\hline Clerical Support Workers & 0.36 & 0.36 & - & 0.12 & 0.12 & - & 0.25 & 0.25 & - \\
\hline Service and Sales Workers & 29.84 & 28.23 & 1.63 & 13.26 & 12.47 & 0.78 & 16.60 & 15.75 & 0.85 \\
\hline $\begin{array}{l}\text { Skilled Agricultural, Forestry and } \\
\text { Fishery Workers }\end{array}$ & 0.15 & 0.15 & - & 0.10 & 0.10 & - & 0.05 & 0.05 & - \\
\hline Craft and related trades workers & 32.09 & 23.02 & 9.07 & 17.45 & 11.62 & 5.83 & 14.65 & 11.40 & 3,25 \\
\hline $\begin{array}{l}\text { Plant and machine Operators, and } \\
\text { Assemblers }\end{array}$ & 10.25 & 10.12 & 0.13 & 5.21 & 5.16 & 0.05 & 5.04 & 4.96 & 0.08 \\
\hline Elementary Occupations & 17.04 & 14.35 & 2.68 & 10.95 & 10.01 & 0.95 & 6.09 & 4.35 & 1,74 \\
\hline
\end{tabular}

It can be clearly seen from Table 8 that the majority of male employees in various industries in Punjab (84.72\%) and female employees are only $15.28 \%$. At the same time, the above data indicates that female employees are mainly engaged in simple low value-added labor such as basic handicrafts and sales service industries. Office staff, professional managers, etc., who need to have a certain cultural literacy, and work with a high level of physical strength, such as agriculture, forestry, and fisheries, rarely involve female employees. This, on the other hand, reflects the employment gender discrimination experienced by local women. It is not just in the employment process, but excludes women at the beginning of employment.

Section III Gender Discrimination of Employment of Female Staff in Rahim 


\section{Yar Khan Region, Pakistan}

Through the analysis of the questionnaires, combined with relevant news reports and the real experience of themselves and their relatives and friends, local female employees may encounter gender discrimination throughout their careers. This includes not only job hunting, job assignments, salary, job promotion, and many other aspects. The following will be discussed in detail with the expertise of the students.

\subsubsection{There is gender discrimination in the job recruitment process}

In today's Pakistani labor market companies occupy absolute dominance. In order to maximize profits, many business owners began to set up checks for female job seekers from the job search and recruitment steps. In the early years, in many corporate recruitment profiles, the terms "only male job seekers", "men only", and "not recommended for female delivery resumes" were clearly written. In the past two years, condemned by public opinion, most companies have deleted similar content in their job advertisements, but this does not mean that gender discrimination in employment for women has been eliminated. Most companies use the method of receiving resumes as long as they meet the requirements, regardless of gender. However, the resumes of female job seekers will be screened out and will be set aside, and female job seekers will not be notified to enter the next round of interviews, even if the conditions of female job seekers fully meet the job requirements. Some companies even notify female job seekers to participate in interviews, and will reject female job seekers in the follow-up interview stage with various seemingly legitimate and even seemingly unjustified reasons.

A case study of a university graduate in Beijing, Cao Ju (a pseudonym), suing Beijing Giant for the existence of gender discrimination in the recruitment process is a typical case. The defendant Giant Company did not indicate that it only recruited men in its job advertisements. Cao $\mathrm{Ju}$ delivered the resume after comparing his own conditions to the recruitment conditions. After a long wait, I did not see a reply, then I contacted the giant company to inquire about the specific reasons. The answer was that the relevant positions were only recruited by male job seekers. Therefore, even if all aspects of Cao Ju's requirements meet the needs of the unit, they will not be accepted. Cao Jufang said that the giant company refused to hire themselves as employment sex discrimination simply because she was a girl rather than her ability to work, and filed a lawsuit in the local court. In the end, the case was compensated by the giant company, and Cao Ju must lose both sides and settle the case. The case was also referred to by the industry as "the first case of 
gender discrimination in employment in China".

China's Cao Ju reached a settlement with the company after receiving compensation from the company, but there are still thousands of "Cao Ju" in Pakistan who are suffering from injustice. The author is from the Rahim Yar Khan area, where the majority of women in the local area are engaged in the so-called "female work" of low wages, low salary levels and poor work links in the handicraft industry and sales service industry. Even so, many of my female relatives and friends also encountered gender discrimination in the process of seeking employment. Taking the job search experience of a female friend of the author as an example, a local travel company informed her to interview after receiving her resume. Although the company did not directly show that it did not want to accept female job seekers, it was significantly more inclined to another male job seeker throughout the interview process, even though her comprehensive conditions were even better. As a result, it is conceivable that the author's female friend was rejected by the company on the grounds of "needing more talented people". In the follow-up with the author to talk about this matter, my friends are annoyed but helpless.

With the constant attention of the society, the gender discrimination of female job seekers in the recruitment process has become more and more hidden. Some enterprises began to play the "edge ball", turning the "male only" that appeared in the job advertisement into a heavy restriction on height, working hours, marriage and childbirth issues. This is obviously another rhetoric of "male only". These so-called additional clauses have become a new obstacle in the process of women's job hunting. Among them, "unmarried and uncultivated" is the fiercest roadblock, this will be discussed in more detail below.

It is true that companies are reluctant to hire female job seekers based on their own interests. In the eyes of employers, male employers need to bear the extra cost of marriage and childbirth problems in a short period of time. In 1958, the Federal Government of Pakistan promulgated the "Women's Yield Welfare Act", which clearly provides that for female employees employed in all businesses in Pakistan, they can enjoy 6 weeks after working in a unit for more than 4 months. Maternity leave. During this period, the company still needs to pay the normal salary of the staff. Businesses pay female employees, but employees cannot create returns for the business. As a company, this deal is obviously not cost-effective. At the same time, most companies believe that female employees will inevitably lose their work efficiency after marriage or after childbirth due to housework and child rearing. This is obviously not what companies are willing to see. The 
employment of male staff is completely without such concerns, and most companies believe that the work efficiency of men in most industries is obviously high. Therefore, considering all aspects, companies are obviously more willing to hire male job seekers with lower overall costs and reject women.

\subsubsection{There is gender discrimination in the job allocation process}

Invisible discrimination in the job allocation process is more subtle than the direct recruitment of "only men" in the recruitment process. According to the results of the questionnaire survey, female employees in the Rahim Yar Khan region of Pakistan are generally engaged in low valueadded labor-intensive industries. The salient features of these industries are low employment threshold, low salary level, and poor working environment. For most female employees, labor security and fair employment are a luxury. This conclusion can also be corroborated by the distribution of the gender-disciplinary industry in Punjab (see Table 8) published by the Federal Statistical Office of Pakistan (http://www.pbs.gov.pk).

As a simple example, in the entire Pakistani society, people based on the inherent gender perception generally believe that women should engage in some simple and easy work that does not require too advanced labor skills, such as sales staff, housekeeping services, nurses, kindergarten teachers, etc. . And in high-tech industries such as computer, medical, and finance, women are not competent. It is precisely because of this that it is easy to see a large number of saleswoman, female nurse, and female kindergarten teachers in Pakistan, and rarely encounter high-level female programmers, female doctors, female scientists, and so on.

An important part of social stratification is actually occupational stratification. The most important basis for judging the social status of a particular social group is to look at the occupational level in which the social group can obtain social employment opportunities. The unequal employment opportunities for men and women in Pakistan are essentially the inequality of gender status. The gender discrimination encountered by female staff in job assignment limits the employment scope of female job seekers to certain so-called "female industries", which affects the realization of women's self-value while restricting the development of social economy.

\subsubsection{There is gender discrimination in remuneration packages}

The most intuitive way to realize the value of a company's employees is to see how much they can get. Employees create value for the company through their own labor. It seems reasonable 
and reasonable for the company to pay a certain salary of the employee as compensation. It should be divided. However, this kind of reason should be reasonable in the Rahim Yar Khan region of Pakistan. According to the data obtained from the questionnaire, the author found that the income of local female staff is generally low. More than $70 \%$ of female employees earn less than 15,000 rupees (about 945 renminbi), and according to public data from the Federal Statistical Office of Pakistan, more than half of male employees earn more than Rs 15,000 a month. It can be reasonably concluded that the income of female employees in Pakistan is generally lower than that of men. According to the Federal Statistical Office of Pakistan (http://www.pbs.gov.pk), the statistical distribution of the salary distribution of the two genders in Punjab, Pakistan, in 20172018 (see Appendix 2) can also support this view.

According to the survey, more and more companies in the local area pay female employees a lower salary than male employees in the same position, and the salary is personal privacy. The staff should not talk about the salary privately to cover up the "substance of different pay for equal work". . What's more, directly in the recruitment stage, the female employees in the same position are paid less than men. This makes the overlord clause that should have been corrected seem to be "legitimate", and job seekers can only accept it in order to obtain a job opportunity. If the relevant labor inspection department checks this later, the company will sign the labor contract to dismiss its responsibility with the employee's consent to the terms.

It is clearly unqualified for Pakistan to measure the degree of gender equality in a country by using the difference in gender pay as an indicator. Along with the continuous development of Pakistan's domestic economy, the salary level of female employees in the Rahim Yar Khan region has Risen sharply compared with the past, but the salary of female employees who have not changed the same position is generally lower than that of male employees.

\subsubsection{There is gender discrimination in the promotion process}

The promotion of female staff today is also a barrier. In Pakistan, female staff have been working for a while. When the position reached a certain stage, the promotion space was significantly reduced. The reason for this phenomenon is not that the female staff's ability to work is not up to the job, but because the business owner comprehensively considers that the female staff cannot fully work because of the child's education problems and the elderly's nursing problems. At the same time, more and more female staff, especially female employees in highlevel positions, are worried about fertility problems affecting their professional development and 
choose to give up their births. This is not a good phenomenon. For the majority of professional women in Pakistan. It is often impossible to give birth to a child and a career. Although the company does not directly indicate in the employee regulations, if the female staff chooses to have children, it means that the company's promotion and salary increase will not be related to you in the future, but also bear the eye in the company.

\section{Section 4 Gender discrimination in employment of female staff in the Rahim Yar Khan region of Pakistan}

The increasingly severe employment situation in Pakistan has led to the fact that local female employees face gender discrimination in their employment process, and the series of problems caused by it cannot be underestimated. The most direct impact of employment gender discrimination on female employees is to combat the enthusiasm of female employees, which in turn leads to loss of work enthusiasm for female employees. As a result, local women's unemployment has become the norm. Data from the Federal Statistical Office of Pakistan (http://www.pbs.gov.pk) show that the urban female unemployment rate in Punjab is as high as $14.92 \%$. The high unemployment rate among professional women in Pakistan is closely related to the gender discrimination in employment they encounter.

Unemployment for local female staff means losing the source of the economy, which will directly lead to a decline in their quality of life. Women who lost their economic resources had to rely on patriarchy in order to survive and were forced to return to their families. For these women, returning to the family means giving up their right to further development. Error! Reference source not found. At the same time, women who lack an economic base can be imagined in the family, not to mention the rights they should have in the family.

In the Rahim Yar Khan region, people are more inclined to position women's social roles as families rather than workplaces. This narrow social orientation makes it difficult for women to get out of the family and get on the job. If society believes that women are affiliates of the family, then business owners will ignore female job seekers during the recruitment process. Without job requirements, the education investment and skills training for women in society will be reduced accordingly, and it will be more difficult for women to get out of the family.

From a family perspective, the relationship between personal career and family life is intertwined; in theory, both husband and wife need to share their responsibilities to the family. 
Balancing family and work obligations should be universally applicable to every family member. However, the reality is that female members of the family often face greater challenges in balancing their personal and family lives. This problem is not specific to a particular industry or certain characteristics of the population, almost all female employees face the above problems in some aspects of their lives. In order to properly coordinate the needs of work and family, it is often necessary for a member of the family to make compromises. As a result, it is conceivable that in most cases, female members of the family will (forced) choose to sacrifice themselves. However, the author believes that the issue of gender discrimination in employment for female employees is not a good thing for men. Female employees have difficulty in employment and the unemployment rate is low. In order to protect family life, it is bound to increase the work pressure of male staff. It is unthinkable if the entire cost of an entire family is borne by one person. Male staff members are under too much work pressure, which will seriously affect their physical and mental health, and naturally it is not conducive to their daily work, if the males in the family are also crushed. Then for this family is the disaster. Therefore, the issue of gender discrimination in employment makes it necessary for women to return to the family as a vassal of men, but also increases the pressure on men's work and life, which is not a good thing for men's own development.

Women's exposure to gender discrimination in employment is not limited to women themselves and their families. The harm caused by gender discrimination in women's employment to the whole society cannot be ignored. It is no surprise that female employees have been treated unfairly by enterprises because of marriage and childbearing problems. Some female employees are in the process of delaying marriage or not getting married for their career development planning. If they are married, they will also choose to speculate or give birth to children. This is an extremely dangerous signal for society, which breaks the harmony that the entire society should have created a series of family conflicts. If all women refuse to enter the marriage hall because of work problems, the emergence of a large number of bachelors will inevitably lead to serious social problems; if every couple of school-age couples choose not to breed offspring for work reasons, then the continuation of society will not be discussed. .

The series of family conflicts caused by the high unemployment rate and low employment rate of women will eventually turn into social instability. The harmony and stability of society cannot be separated from the harmony of the family and the harmony between the two sexes. The key to ensuring gender harmony is to equal employment with women. Ensuring equal employment 
of women is the key to maintaining harmony between the two sexes. Gender harmony, family harmony and social development can last long.

In summary, the harm of female employees to employment sex discrimination is not only for female employees themselves, but also for family harm including deepening family conflicts and undermining family stability and unity. The accumulation of a large number of family conflicts will inevitably lead to more serious social problems. Therefore, the author believes that the issue of gender discrimination in women's employment has become one of the most urgent social problems in today's society.

\section{Section V Recommendations for Eliminating Gender Discrimination in Employment of Female Staff in Rahim Yar Khan Region, Pakistan}

Since the beginning of the new century, people have gradually begun to use the level of the social status of a country's female citizens to measure the progress of social civilization in this country. Whether women encounter gender discrimination in the workplace is an important manifestation of the status of women in society. This year, Pakistan's domestic economic growth rate is sluggish, labor force is flooding into the market, and the unemployment rate remains high. The form of employment faced by female staff is even worse, and the gender problem of women's employment is even more severe. On the basis of guaranteeing women's professional employment rights and economic benefits, it is a worldwide problem to eliminate the gender discrimination that women encounter in the workplace. The government, society, and academic circles have invested huge amounts of manpower and resources to find the optimal solution to this problem. Based on his own professional knowledge, the author provides several countermeasures and suggestions for eliminating the gender discrimination in employment of female employees in the country according to the current situation of gender discrimination in employment in women in the Rahim Yar Khan region of Pakistan.

\subsubsection{Promote economic development and create jobs}

As mentioned above, the root cause of women's gender discrimination in employment in Pakistan is the economy. The key to "breaking" is to accelerate economic development and create jobs as much as possible. The rapid development of the national economy is bound to provide a large number of jobs for the society, which can fundamentally alleviate the employment dilemma and lay the foundation for alleviating gender discrimination in women. The rapid development of the economy will inevitably lead to the escalation of domestic industrial challenges. For Pakistan, 
it is fully beneficial to promote the transformation of domestic industries and increase the proportion of the tertiary industry in the domestic industrial structure for the prosperity of the female employment market.

Since the 1990s, Pakistan's domestic economic system has collapsed due to wrong economic policies. The 2008 financial crisis has further worsened the domestic economic situation. Although the economy has improved under the continuous efforts of the people throughout the country, the current position that the society can provide cannot meet the demand. Because of this, women in the Rahim Yar Khan area face great employment dilemmas. Women are often discriminated against in limited job competition.

Relevant research shows that there is a big gap in the demand for community services in large and medium-sized cities. Women are more communicative and more affable than men. In this regard, female staff can participate in more social work or community service. Compared with modern industries such as finance and technology, community service work has lower physical requirements for practitioners, and it is flexible working time. It does not require practitioners to have higher education. It can provide a large number of suitable jobs for local women. Take into account the needs of women to care for their families.

While creating jobs as much as possible, the government also encourages self-employment and flexible employment to expand employment channels. This is beneficial to ensuring equal employment for women. Encouraging self-employment and flexible employment does not mean encouraging women to start their own businesses and leaving ready-made jobs to men. Instead, provide another employment idea for women who have not found a job or have left for some reason. For the time being, the Rahim Yar Khan region has a large rural population and the female personal literacy is generally low. Therefore, flexible and diverse employment not only takes into account the job needs of different female job seekers, but also has a positive impact on the country's economic development.

\subsubsection{Promoting the concept of social change}

The concept of promoting social transformation mentioned here mainly includes two parts: one is to promote the inherent prejudice of social change for women, and the other is to accelerate the transformation of business ideas.

Pakistan has been founded less than a hundred years ago, but Muslim culture has been passed 
down through the millennium. The same is true in the Rahim Yar Khan region. Traditional Muslim culture has a long-standing prejudice against women, which is one of the sins that need to be abandoned in Muslim culture. The idea that women are subordinate to men has long been in the hearts of the people, and most women in the local area are only busy at home for the rest of their lives. The key to solving this problem is to promote the transformation of the inherent concept of the whole society and eliminate the gender discrimination and gender bias brought to the workplace by traditional religious and cultural ideas. Modern research has confirmed that both men and women have different working abilities. Some jobs are suitable for male staff, but there are also many jobs that are more suitable for women. In the recruitment process, business owners should start from the position itself and abandon gender bias to find the most suitable staff. Everyone in society should make their own efforts to eliminate gender bias.

The government can play the role of the government by establishing a typical case of female employment and launching a female star in the workplace. At the same time, social media should also actively promote publicity, which is intended to guide public opinion to guide the public to promote the idea of equality between men and women. The above measures are intended to change the society's inherent perception of gender differences, advocate social fairness and objective evaluation of women's work ability, and ensure that women's participation in work is the same as men. The fact that female employees encounter gender discrimination is a microcosm of gender discrimination. As long as society changes its mindset, the problem of gender discrimination faced by female employees naturally ceases to exist.

In the Rahim Yar Khan region, most of the female members of the family are not only responsible for raising children to care for the elderly, but also for cumbersome housework. Male members of the family work mainly outside to support the family. However, with the popularization of education for all and the continuous development of science and technology, the job requirements for job seekers are less important. It is fortunate that more and more women are starting to leave the family and participate in social work with men.

In order to further solve the "worries of women", they can safely walk out of the family and participate in work. Government departments should improve community services in the city as much as possible, and establish similar institutions in the village to realize the marketization of housework. For example, vigorously promote the construction of kindergartens, temporary custody institutions, nursing homes, health care hospitals, etc. to alleviate the burden of female 
staff for childcare and pension; at the same time vigorously promote domestic service, and widely start convenience stores such as fast food restaurants and laundry rooms, so that women can be burdened on the one hand. Freed from the chores of homework, and able to provide jobs for some women with lower education levels. The above measures can liberate women to a certain extent, but female employees still have to invest a certain amount of time and energy for the family. Therefore, in the promotion of domestic marketization projects, European countries can be emulated to encourage men to participate in domestic work, including taking care of women during pregnancy and raising young children to take care of their parents, so as to avoid female employees losing development opportunities due to domestic work.

In today's society, women have the same rights as men to assume social responsibility. Sex discrimination requires women to return to the family is clearly debatable. This kind of employment gender discrimination not only limits women's ability to play their talents, but also causes huge waste of social human resources. At the same time, it promotes the concept of promoting patriarchal society, making it difficult to achieve equality between men and women in the whole society. Female staff is an important part of the modern workplace. With the continuous advancement of technology, the requirements for professional physical strength in the workplace have gradually faded. The modern workplace provides a large number of jobs for women with higher comprehensive education in higher education. This not only promotes the continuous progress and development of society, but also continuously enhances itself. In today's knowledge economy, people began to pay more attention to the educational level of women. More and more families are willing to invest in the education of female members of the family. If women's education investment for many years cannot maximize her role, this is a great waste of social resources [24].

All in all, the elimination of female gender discrimination begins with the promotion of social change. Society should gradually abandon prejudice against women, face women's social status and social values, and recognize women's contribution to social development. The cooperation between men and women is the only way to promote social development. The World Bank policy research report clearly states that gender discrimination seriously restricts the development of social productivity. As an indispensable and important component of human development, if the development of women lags behind the overall social development, it will inevitably affect the progress and development of the whole society. People should not simply regard the equilibrium, 
equity and coordination problems faced by the development of the two sexes as gender issues. They should be elevated to important social issues related to social development and solved by the strength of the whole society.

In the daily business process, the company does not necessarily need to give certain preferential treatment or special care to female employees, but at the very least, it should protect the legitimate rights and interests of female employees. For example, in the recruitment process, people should be selected according to the position, and gender should not be deliberately emphasized. If the requirements of female job seekers meet the needs of the company, they should be hired. Not to be hired because it is a woman. Secondly, there should be no difference between men and women in job allocation. Unless very few jobs can only recruit men because of job requirements, the conventional industry should be based on the ability of heroes, rather than the gender-based industry entry threshold, the society can accept female nurses, saleswoman, should be equally acceptable to female doctors, women Scientists, etc. Ability has never been related to gender. Again, the salary allocation should be based on post compensation. Employees who are able to successfully complete their work tasks should receive a salary that matches their position, regardless of their gender. Women can do the same job as men, and there is no reason to earn a three-pointer for a short man. Ensuring the equal pay for equal work of both sexes is the company's respect for all staff. Finally, in terms of job promotion, companies should not be different between men and women. If a female employee's ability to work is capable of a higher level of work, it should be appreciated. This is an affirmation of the ability of employees to work, and it is also an important guarantee for the steady development of the company.

\subsubsection{Urge women to improve their literacy}

The most important thing in eliminating gender discrimination in women's employment is the improvement of the quality of female employees. Combine the actual situation in Pakistan. The following will discuss specifically how women can improve their literacy.

Pakistan is deeply influenced by Muslim culture and patriarchalism is deeply rooted in the hearts of the people. Not only do men think that "women are subordinate to men", but many women in the locality share the same concept, which is worrying. Therefore, it is particularly important to correctly guide Pakistani women to change their mindset and face women's social status and social values. Women should be clear about the subjective consciousness. The female subjective consciousness referred to here should not only be reflected in the female's ideological 
aspect, but also need to respond in the female workplace behavior.

The embodiment of subject consciousness in women's thinking first requires women to be right in their own social status and dare to challenge the traditional concept of "women are subordinate to men". At the same time, establish the idea of equality between men and women. Female employees have to believe from the bottom of their hearts that men who work as social workers for men can do the same. The manifestation of subjective consciousness in women's workplace behavior requires women to exert their subjective initiative to strive for a world of their own in the Pakistani workplace where men are dominant.

Among the many factors that lead to gender discrimination in women, the low quality of women is the most fundamental reason. In Pakistan, for example, $80 \%$ of the country's more than 200 million people live in rural areas. Rural women lack cultural education and their personal literacy is generally low. In a sense, it is equivalent to "new age illiteracy". Even if the society continues to develop and advance, it can provide a large number of jobs, but they are also difficult to adapt to the needs of the new era, and it is impossible to go to the workplace smoothly. Therefore, one of the fundamental ways to solve female gender discrimination is to urge women to improve their own quality, which is also a prerequisite for women to participate in social labor.

First, basic education should be further promoted throughout Pakistan, and ensuring that girls in the widest rural areas of Pakistan can receive education is the cornerstone of eliminating gender discrimination in women. Education must start from the dolls, similar to the "nine-year compulsory education" promoted by China is a good reference. Secondly, most women in Pakistan have low cultural literacy and in most cases engage in low-level labor. Government departments can help the low-cultural literacy groups to grasp the socially scarce work skills and improve their workplace competitiveness by setting up labor skill training schools or regularly organizing skills training. In Pakistan, this applies not only to female employees, but also to male job seekers.

The Pakistani labor market is still in a state of severe saturation today. Superb personal quality is an important guarantee for women to be invincible in the workplace competition. Not afraid of others being better than you, I am afraid that you will work harder than you. In the workplace, women face competitors' not only excellent male staff, but also better female competitors. All you have to do is try to make yourself better.

\subsubsection{Accelerate the construction of anti-discrimination legal system}


The most effective way to solve female gender discrimination is to oppose the construction of a gender discrimination legal system. Therefore, Pakistan needs to speed up legislation to improve the pace of domestic anti-sexist legal system construction, which is also an important guarantee for achieving equal employment for women.

First of all, it is necessary to clarify the criteria for the identification of gender discrimination, and to clarify the meaning and extension of gender discrimination in the form of legal provisions, and can attach typical cases if necessary. For example, the most common "male only" in the recruitment process is the most obvious gender discrimination. A clear identification standard is conducive to the labor inspection department to quickly and accurately determine whether female employees encounter gender discrimination.

Secondly, it is necessary to establish and improve a system of rules for ensuring equal employment for women in the whole society. Specialized single-line laws and regulations can be formulated for gender discrimination, and the content of women's employment rights and interests can be defined from the legal level, so as to effectively protect the rights and interests of female employees in equal employment. Really have a law to rely on.

Third, the labor inspection department should be urged to supervise the enterprise to act in accordance with its law in its daily production and operation activities. It is intended to prevent gender discrimination in women and protect the legitimate rights and interests of female employees. At the same time, avoiding anti-discrimination laws and regulations is a dead letter.

Finally, we must increase the illegal cost of the company. As mentioned above, gender discrimination for women is the choice of enterprises to maximize profits under the guidance of market rules. Then the best solution to this problem must start with the economy. Although there are many laws and regulations in Pakistan that prohibit companies from refusing female job seekers because of gender factors. However, the penalties for illegal enterprises are confusing. For most enterprises, the illegal cost is too low, which also objectively condone corporate crimes. Therefore, the illegal cost of the enterprise should be greatly increased in the revision process of the follow-up law. It is hoped that business owners will take the initiative to treat female employees equally and discard gender discrimination. At the same time, women's rights to be held accountable should be retained. If women are subject to gender discrimination in employment and have evidence, then women have the right to claim compensation from the company. It is a 
guarantee to violate the law.

In order to avoid the laws and regulations that have been promulgated against gender discrimination will not be reduced to a piece of paper, to ensure that female employees have "complaints with complaints" when their legitimate rights and interests are violated, it is necessary to establish a special anti-sexism department across Pakistan. Ensure that the corresponding laws and regulations are truly implemented, and strengthen the implementation of relevant laws and regulations. This department can be listed either in the government function or in the labor inspection department.

Once a woman encounters sex discrimination in employment, she can immediately seek help from the local anti-sexist department. After receiving the help from a female employee, the antisexist discrimination department should immediately check the problems reflected by the female staff. If the company is found to have committed illegal activities, the relevant responsible person should be punished. At the same time, it is obligatory to oppose gender discrimination and publish the results of the investigation and the opinions of the treatment to the public within the prescribed time. In addition, the anti-sexist discrimination department can also promptly report the problems arising in the implementation of anti-discrimination laws and regulations to the Pakistani legislative department (Pakistan Congress), so as to continuously revise and improve the antidiscrimination laws and regulations system, and provide a solid foundation for promoting equal employment for men and women in Pakistan. Legal backing.

\section{Section VI Summary of this section}

This chapter is the key chapter of the full text, mainly to analyze and discuss the problems reflected by the questionnaire. It mainly includes a detailed description of the gender discrimination in employment of female employees in the Rahim Yar Khan region of Pakistan and a brief description based on relevant cases. At the same time, it discusses the three aspects of employment gender discrimination for the causes of women's causes, individuals, families and society. The second is to analyze the results of the results of the local women's employment gender discrimination and the related research results, and to discuss the relevant incentives listed. Finally, based on his professionalism and the above research contents and previous research results, the author proposes some suggestions for improving the gender discrimination in employment of female employees in the Rahim Yar Khan region of Pakistan. 


\section{Conclusion}

The status of women's social status is an important indicator of the country's modernization development process, and the status of women's employment is an important manifestation of women's social status. Pakistan is currently in an important transition period of social and economic development. The domestic female employment situation is not optimistic, mainly due to the low proportion of female employment, the low level of employment of female employees, the low quality of female employees, and the widespread gender discrimination among women. This has become a serious social problem. If we let it develop without taking measures, it will seriously restrict the speed and quality of Pakistan's domestic economic development.

The first-hand information on the employment status of professional women in the Rahim Yar Khan region of Pakistan was obtained through questionnaire survey, supplemented by the public data of the Federal Statistical Office of Pakistan, and combined with the research results of previous studies to explore the employment of professional women in Pakistan. Gender discrimination. The results show that female employees in all walks of life in the Rahim Yar Khan area have encountered or are facing gender discrimination. It is reasonable to assume that it is common for female employees across Pakistan to experience gender discrimination. Due to the existence of gender discrimination, the legal rights of female employees are not guaranteed. Although the phenomenon of direct refusal of women in the recruitment process has changed with the joint efforts of the government and the society, enterprises can basically guarantee equal pay for equal work for men and women. However, there is still room for improvement in the issue of female invisible gender discrimination in the settlement of job assignments and job promotion. The complete elimination of gender discrimination in women in Pakistan has a long way to go.

Through the collection of the data obtained from the questionnaire, the author found that the incentives for Pakistani professional women to encounter gender discrimination are multifaceted. Dominance is undoubtedly an economic factor, mainly including the imbalance between the supply and demand of labor and the pursuit of maximum profits. At the same time, the traditional cultural factors of Muslim society, women's own comprehensive literacy is poor, and Pakistan's domestic anti-employment gender discrimination legal system is imperfect, and the lack of relevant social security system are the key factors that cause local female employees to encounter gender discrimination in employment. Therefore, in my opinion, the problem of gender discrimination in employment faced by Pakistani women is no longer a simple economic problem, 
but rather a social problem dominated by economic factors.

In recent years, Pakistan's domestic economy has been sluggish and its population has grown too fast. The influx of large numbers of people into the labor market and the lack of corresponding positions will inevitably lead to an imbalance in the supply and demand of local labor. Enterprises in the market economy pursue the maximization of interests as the ultimate goal, and female job seekers obviously do not meet the needs of enterprises. So women are well aware of the gender discrimination in employment in their careers. Regardless of economic issues, Pakistan, as a typical Muslim country, is full of gender discrimination against women. Moreover, local residents, including many women, believe that it is normal for women to encounter gender discrimination in employment. Of course, this is related to the fact that women in Pakistan are generally undereducated and their personal literacy is poor. It is precisely because of this that local women can only engage in low-level labor in most cases and cannot enter high-tech industries. At the same time, due to the need to improve the relevant labor security legal system in Pakistan, the illegal cost of enterprises is almost zero. This makes the wrong behavior of enterprises not effectively restrained. Objectively, the problem of female employees in Pakistan encountering gender discrimination in employment is more serious. The protection of the legitimate rights and interests of female employees can only become a slogan.

Women's gender discrimination in employment is a universal problem. In any country in the world, gender discrimination may exist as long as women are involved in the work. Based on Pakistan's basic national conditions and relevant professional knowledge, the author provides the following suggestions in order to eliminate the problem of gender discrimination in employment for local female employees in Pakistan.

1) The Pakistani government should accelerate the reform of the economic system, thereby further promoting the domestic economic growth, increasing the number of positions, and alleviating the imbalance between the supply and demand of labor. At the same time, encourage self-employment and provide corresponding policy support. A variety of measures are also intended to address local gender discrimination in employment for women.

2) The government's leadership accelerates the transformation of the concept of the whole society. On the one hand, it requires the whole society to correctly understand the social status and social contribution of women, and strives to bring the concept of equality between men and women 
into the hearts of the people. It is intended to encourage qualified women to go out of the family to participate in social work. At the same time, correctly guide corporate values. Enterprises should not unilaterally pursue the maximization of interests, and should take the initiative to assume social responsibilities. Guarantee the legitimate rights and interests of female employees in all aspects of recruitment, job assignment, salary and promotion.

3) On the basis of the government's all-round creation of a good employment environment for women, women should also actively and consciously improve their literacy. Including not only active learning advanced cultural knowledge and professional skills. For the professional skills that have already been mastered, you must study harder and make yourself more and more progressive. At the same time, families should guarantee that girls of the appropriate age receive the education they deserve, so that they can gather their strengths in the workplace in the future.

4) The Pakistani government should improve the domestic legal system against gender discrimination in employment as soon as possible. Clarify the definition of gender discrimination in employment and make laws available. At the same time, in order to ensure that the relevant legal system will not become a waste paper, the relevant responsible departments should urge all enterprises and employees of the whole society to strictly abide by relevant laws and regulations in their workplace life, so as to have a legal basis. Then there are clear relevant law enforcement departments. For the illegal activities of enterprises, find them together, investigate and deal with them, and never tolerate them. Effectively protect the legitimate rights and interests of female employees from infringement.

\section{References}

[1] Mei Anni. Pakistani education cognition from the perspective of women and religion [J], Business, 2013 (46) 275-276.

[2] Iffat Hussain. Problems of Working Women in Karachi, Pakistan. Cambridge Scholars Publishing, 2008.

[3] Sayida Razna Kabir, and Hongmei. A comparative study on the leadership of women in Bangladesh, India and Pakistan in public affairs [J]. Southeast Asia South Asia Studies, 2015(01): 87-94+110.

[4] Li Jin. From the perspective of labor supply and demand, the gender discrimination in employment in China

[J]. Economist. 2004 (2).

[5] Gary Becker. The Economics of Discrimination. University of Chicago Press, 1971: 266P.

[6] Hu Xueqin, Li Xiaofu. Labor Economics [M]. China Economic Publishing House, 2011.

[7] Yu Hong. Is a woman born to be weak? Labor economy and human resource management [J].2000(9). 
[8] Gary S. Becker. Economic Analysis of Human Behavior [M]. Shanghai People's Publishing House, 1995.

[9] Gary Becker. Human Capital. Columbia University Press.1975

[10] Ridgeway Cecilial. Interaction and Conservation of Gender Inequality Considering Employment. American Sociological Review, 1997:218-235.

[11] Liu Dezhong, Niu Zengxiu. Occupational gender segregation and female employment [J]. Women's Studies. 2004 (4).

[12] Zhang Lianzhen, Women's Issues in Reform [M]. Jiangsu People's Publishing House, 2002.

[13] Cai Fang. Characteristics of Female Labor Supply and Investment in Education [J]. Jiang Hai Academic Journal, 2004 (6).

[14] Li Junfeng. Analysis of the causes of women's employment and development dilemma [J]. Population Journal. 2006 (5).

[15] He Lihua. Population, Labor and Employment in Pakistan, Business Office of the Consulate General in Karachi, 2010.

[16] Dubai Cares. Baseline Assessment Study Report District Rahim Yar Khan, Idara-e-Taleem-o-Aagahi (ITA), 2013.

[17] Ayesha Khan. Pathways of Women's Empowerment South Asia Research Programme Pakistan Scoping Paper. Collective for Social Science Research Karachi, 2007.

[18] Nasreen Akhter, Rafaqat Ali Akbar. Critical Analysis of Life of Pakistani Women: Views of Educated Women. Journal of Elementary Education, 2016 (26), 111-121.

[19] Jacob Münsell. Labor Supply Research [M]. China Economic Publishing House, 2003.

[20] Shen Hongtao. Research on Youth Unemployment in Pakistan from the Perspective of China-Pakistan Economic Corridor [D]. Lanzhou University, 2018.

[21] Fan Ruolan. A Survey of Women's Employment in Pakistan [J], China Women's Movement, 1995, 46-47.

[22] China Xinbao. Pakistan Economic and Business Environmental Risk Analysis Report [J]. International Finance, 2018 (10): 67-71.

[23] RIAZ Ahmad, Mi Hong, AMIN Ullah, et al. Challenges faced by female micro-entrepreneurs - Coordination measures for personal work and life of female entrepreneurs in Pakistan [J]. Journal of Suzhou Vocational University, 2018, 29 (04): 9-13+29.

[24] Luo Fengjuan, Mo Haiwen. The Ideal Pursuit and Realistic Dilemma of Gender Equity in Basic Education-Analysis of Girls' Education in Pakistan [J]. Foreign Elementary and Secondary Education, 2015(08): 5-10+4.

[25] Huang Zhiling, Yao Xianguo. Research on Gender Differences in Educational Return Rate [J], World Economy, 2007 (07).

[26] Yun Hui. Research on gender discrimination in Chinese women [D]. Harbin Engineering University, 2007.

[27] Wang Qichao. Benazir Bhutto and the improvement of the status of women in Pakistan [D]. Diplomatic Academy, 2011 
[28] Jin Window Love. Research on Contemporary Women's Employment in China [D]. Northeast Normal University, 2012.

[29] Yang Yong. Research on the Legal System of Anti-Employment Discrimination in China [D]. Northwest University, 2016.

[30] Zhang Hui. Research on Female Employment in the New Normal [D]. Xinyang Normal University, 2017.

[31] Zhai Zhijiang. Poverty Status and Anti-Poverty Path in Pakistan [D]. Lanzhou University, 2018.

[32] Zhu Yi'an, Bai Hua. Women and Gender [M]. Shanghai Education Press, 2003.

[33] Su Hong. The Gender View from Multiple Perspectives [M]. Shanghai University Press, 2004. 